\title{
Começar pelo meio de um fazer: recompor o ensino de sociologia
}

\author{
Graziele Ramos Schweig ${ }^{1}$ \\ ORCID: 0000-0003-0590-9742
}

\section{Resumo}

A partir do debate contemporâneo acerca da virada ontológica, busca-se discutir neste artigo possíveis implicações de seus pressupostos para conceber as práticas da docência da sociologia na escola básica. A educação e o ensino são pensados deslocando-se do questionamento epistemológico (como conhecer) para aquele da ontologia (como a realidade se produz), de modo a abrir um campo de atenção à materialidade das práticas de conhecimento. Explora-se essa perspectiva tendo como disparador o relato de uma situação de planejamento pedagógico oriundo de pesquisa de campo etnográfica realizada em Porto Alegre, Rio Grande do Sul. Ao se desdobrar as controvérsias contidas na narrativa, tensionam-se os limites do idioma representacional na concepção da docência da sociologia no ensino médio. Questiona-se, portanto, qual ensino seria possível ao assumirmos que não há um mundo - e uma sociologia - prontos previamente às práticas. Assim, ao explorar os caminhos indicados no próprio relato de campo, elabora-se a ideia de "começar pelo meio de um fazer" em uma proposição de inversão e transmutação dos elementos implicados na intervenção pedagógica na escola. Com isso, concebe-se a prática docente menos em termos normativos e finalísticos e mais a partir da ideia de abertura às recalcitrâncias e cultivo da atenção a processos e percursos.

\section{Palavras-chave}

Ensino de sociologia - Virada ontológica - Prática docente - Etnografia - Antropologia da educação.

$\overline{\text { 1- Universidade Federal }}$ de Minas Gerais, Belo Horizonte, MG, Brasil. Contato: graziele.schweig@gmail.com 


\section{Start from the middle of making: recompose Sociology teaching*}

\section{Abstract}

Considering contemporary debate on the ontological turn, this article seeks to discuss possible implications of its assumptions to understand Sociology teaching practices in school. Education and teaching are conceived by detaching from epistemological debate (how to know) and approaching to that of ontology (how reality is produced), as a way to open a field of attention to the materiality of knowledge practices. This perspective is explored having as a triggering the fieldnote of a pedagogical planning situation observed during an ethnographic research carried out in Porto Alegre, Rio Grande do Sul, Brazil. As the controversies contained in the narrative unfold, they show the limitations of representational language to describe Sociology teaching in high school. Therefore, one might wonder: what kind of teaching would be possible when we assume that there is no world - nor Sociology - ready before everyday practices? Thus, as the article explores the tracks indicated in the fieldnote itself, it leads to the idea of "starting from the middle of making" as a proposition of inversion and transmutation of the elements involved in pedagogical intervention in school. Hence, teaching practice is conceived less in normative and finalistic terms, but more in the idea of openness to recalcitrances and cultivation of attention to processes and paths.

\section{Keywords}

Sociology teaching - Ontological Turn - Teaching Practice - Ethnography - Anthropology of Education.

\section{Introdução}

Recentemente, algumas abordagens da antropologia, da filosofia e dos estudos sociais da ciência e da tecnologia têm tomado a ontologia como foco de preocupação, contrapondo-se à perspectiva representacional. Ao invés de conceberem várias visões acerca de uma realidade única - na esteira do relativismo cultural - explora-se a existência de vários mundos, múltiplas ontologias, as quais emergem nas práticas cotidianas de humanos e não humanos. É nesse sentido que Viveiros de Castro (2002), em suas pesquisas sobre o xamanismo ameríndio, evidencia a existência de um multinaturalismo, o qual se diferencia do multiculturalismo ocidental. Em direção similar, Steil; Carvalho (2014) chamam a atenção para a emergência de um novo realismo ou novo materialismo, que busca se afastar de uma razão semiótica, a qual por muito tempo alocou como objeto das

2- Sou grata às trocas feitas com os artistas Angela Francisca Almeida de Oliveira e Rafael Araújo. Também agradeço aos pareceristas anônimos da revista e à leitura prévia e incentivo de Pedro Rodrigues da Silva, Marcelo Moura Mello, Arllan Maciel Cunha Alves e João Pedro Marques Mourão. 
ciências humanas apenas o significado, tomado à parte da matéria e da corporalidade (STEIL; CARVALHO, 2014, p. 164). Assim, a perspectiva ontológica acaba por questionar uma série de dicotomias que estruturam a tradição ocidental, como mente e corpo, cultura e natureza, sujeito e objeto.

Nesse movimento, diferenciando-se de uma abordagem epistemológica - que se ocupa da perspectiva de um sujeito que conhece uma dada realidade -, a preocupação com a ontologia leva-nos a questionar os modos pelos quais a realidade é constantemente produzida; ou "coproduzida" (MOL, 2002). Descentra-se do sujeito racional como principal agente e passa-se a reconhecer outras formas de agência, não apenas humana. Sendo assim, a matéria deixa de ser considerada como algo inerte, à espera da atribuição de um significado ou da impressão de uma intenção subjetiva. Do contrário, atenta-se para os modos em que a matéria transborda, entrelaçando-se em emaranhados de vida que não podem ser contidos (INGOLD, 2012). 0 conhecimento, portanto, passa a ser considerado menos em seu caráter descritor de uma realidade pré-existente e mais como uma ação de composição com outros - humanos e não-humanos.

Deslocando-se ao campo da educação, propomos discutir as implicações dessa "virada ontológica" (SOUZA, 2015; TADDEI; GAMBOGGI, 2016) para as práticas da docência. Primeiramente, quando pensamos a educação nessa lógica, deixamos de mapear posições teóricas e concepções pedagógicas enquanto representações ou conjuntos de ideias previamente concebidas. Diferentemente, interessa-nos dar primazia às práticas e aos modos como distintos agentes performam uma realidade a todo momento emergente. Interessa-nos abrir um campo de investigação acerca das maneiras como significado e matéria misturamse na feitura de mundos. Para tanto, propomos discutir algumas consequências dessa abordagem tomando como ponto de partida uma situação vivenciada durante a pesquisa de campo etnográfica que deu origem à tese de doutorado Aprendizagem e ciência no ensino de sociologia na escola: um olhar desde a antropologia (SCHWEIG, 2015a).

Algumas pesquisas em educação, relativas a outras tradições disciplinares como a Física e a Biologia, têm incorporado referenciais que questionam a dicotomia humanos e não humanos, pensando suas implicações para o ensino ${ }^{3}$. No entanto, o campo do ensino de sociologia pouco tem explorado as potencialidades dessas críticas - a despeito do fato delas serem mobilizadas para investigar objetos mais centrais na agenda de pesquisa das ciências sociais. Buscando suprir essa lacuna, a pesquisa de doutorado mobilizou discussões teóricas contemporâneas da antropologia para investigar especificamente o tema da aprendizagem da docência da sociologia na escola básica, sendo que boa parte do trabalho de campo etnográfico ocorreu em espaços de formação de professores. No percurso da escrita, a cena escolhida para ser explorada neste artigo acabou não fazendo parte do texto final da tese. No entanto, permaneceu reverberando e provocando novas investigações, ressurgindo aqui com outras traduções.

A partir do trecho narrado, busca-se atentar às divergências e hesitações presentes em uma situação de planejamento de uma intervenção pedagógica. Inspirando-se na perspectiva da "ciência em ação" de Bruno Latour (1994), a proposta é abrir a “caixa-preta”

3- Temos exemplos especialmente na área do Ensino de Ciências, que tem se aproximado da Teoria Ator Rede, de Bruno Latour. Ver, por exemplo, Lima; Ostermann; Cavalcanti (2018). 
do planejamento pedagógico e captá-lo em suas controvérsias e no que elas mobilizam a respeito do ensino de sociologia de modo mais amplo. Para isso, são retirados alguns extratos da narrativa, os quais são explorados ao longo do texto, levando a conceber o "ensino de sociologia no ensino médio" não como um objeto pronto, coerente de antemão, mas como uma "coisa que vaza" (INGOLD, 2012), que tem sua razoabilidade e uniformidade sempre provisórias e constantemente renegociadas em ato. Essa percepção menos fixa visa a criar uma aproximação ao ensino de sociologia como "acontecimento" (DELEUZE, 2003), sem tentativas de delinear uma coerência prévia no âmbito dos significados ou de afirmar uma proposta normativa. Tal movimento, longe de conferir fragilidade ao ensino da sociologia, busca fortalecê-lo em seu potencial de composição e abertura. Por fim, explorando-se os próprios dilemas e caminhos propostos pelo relato de campo, a investigação atenta-se às potencialidades que o "fazer" pode oferecer ao ensinar e aprender sociologia na escola.

\section{Abrir a caixa-preta do planejamento pedagógico}

A pesquisa de campo, realizada por meio de observação participante e entrevistas em profundidade, ocorreu entre 2013 e 2015 na cidade de Porto Alegre e região metropolitana. Além de observar a prática docente de professores com diferentes anos de experiência, dediquei-me especialmente a acompanhar espaços de formação de professores de sociologia - como as aulas do estágio docente da licenciatura em ciências sociais, seminários e reuniões do Programa Institucional de Bolsas de Iniciação à Docência (PIBID), no âmbito da Universidade Federal do Rio Grande do Sul (UFRGS). Junto das atividades na Universidade, acompanhava mais de perto alguns licenciandos nas escolas onde realizavam estágio docente, em reuniões de orientação, além de me inserir nas atividades das duas escolas da rede estadual vinculadas ao PIBID de ciências sociais.

Cada uma das escolas do PIBID tinha um supervisor, professor de sociologia, que ficava responsável por seis bolsistas, estudantes de licenciatura de diferentes períodos do curso de ciências sociais, sendo que alguns deles também estavam matriculados no estágio docente. As atividades dos bolsistas consistiam em observação de aulas e produção de diários de campo, criação e execução de oficinas nas escolas, além de reuniões com as professoras orientadoras na Universidade e com os respectivos professores supervisores para avaliação e planejamento das atividades.

Dessa forma, ao longo de boa parte da pesquisa de campo, eu acompanhava alguns desses professores em formação em diferentes momentos da semana. Assim, logo no início da pesquisa, em Setembro de 2013, durante uma greve do magistério estadual, participei de uma reunião que os bolsistas do PIBID decidiram organizar de forma independente, sem a presença dos supervisores da escola e das orientadoras da Universidade. A proposta era pensar formas de atuação dos bolsistas no período de greve, aproveitando o fato das aulas estarem suspensas, mas havendo possibilidade de realizar atividades com os estudantes do ensino médio.

Nesse encontro, sem supervisores ou orientadoras, a reunião foi realizada em um ambiente informal do Diretório Acadêmico na Faculdade de Educação da UFRGS, onde estavam presentes oito bolsistas. A discussão acerca de como planejariam as atividades 
acionou uma cadeia de divergências que materializaram algumas tensões em torno do ensino da sociologia, as quais retornaram em momentos subsequentes da pesquisa de campo - por isso a escolha desse momento como disparador das reflexões desenvolvidas aqui. No início da reunião, era visível que boa parte dos bolsistas estava mobilizada pela possibilidade de aproveitar o caráter mais livre da greve para propor metodologias diferentes das aulas tradicionais, como dinâmicas e jogos.

Um bolsista, no entanto, ressalta a importância de se fazer também uma "aula expositiva seguida de debate" acerca da greve, de modo a "levar a visão sociológica”, com alguns autores, análise de conjuntura e exemplos. Alguns bolsistas problematizam a ideia de exposição, lembrando da importância de os estudantes serem "mais protagonistas". 0 primeiro replica dizendo que seria importante "ter um embasamento", preparar uma fala sobre o histórico das greves, ver como cada governo lidou com isso, como a mídia retratou, "para começar a fazer sociologia". Todos concordam que isso demandaria "bastante preparação prévia" e eles não sabiam se teriam tempo para isso.

Em meio à conversa, alguém sugere fazer uma oficina de estêncil. 0 grupo parece achar interessante. Perguntam-se se seria melhor localizar o momento do estêncil antes ou depois do debate com os alunos. Um bolsista, que vinha de uma trajetória de atuação e docência no teatro, defende que primeiro se faça a prática do estêncil, para depois debater. Outros dois bolsistas defendem o inverso, ressaltando que os alunos poderiam mudar de ideia depois do debate e então o estêncil já estaria feito. 0 primeiro bolsista argumenta que "o próprio fazer da atividade já seria problematizador". Se deixassem para produzir o estêncil depois do debate, pareceria que os alunos tinham de fazer um "trabalhinho" para mostrar que compreenderam o conteúdo. Do contrário, segundo ele, poderiam "ver o que eles estão pensando, retomar a produção deles durante o debate e partir dela para discutir”.

\section{“Levar a visão sociológica”}

Sendo a sociologia notadamente feita de uma pluralidade de perspectivas, embates teóricos e possibilidades metodológicas, o que os bolsistas do PIBID querem dizem quando falam em "levar a visão sociológica" aos estudantes? Como se constrói essa suposta singularidade dentro da pluralidade? De saída, o próprio nome do componente curricular nem sempre evidencia a diversidade que contém. A denominação "sociologia" deve-se menos a justificativas teóricas ou pedagógicas e mais a caminhos políticos. Além de ter mobilizado mais os chamados sociólogos nos debates que reivindicaram seu retorno recente aos currículos escolares, o nome sociologia foi escolhido por ser mais difundido, angariando maior legitimidade para sua inclusão como componente curricular (PEREIRA, 2013). No entanto, se percorrermos os textos das normativas legais, nomeadamente são os saberes das ciências sociais - antropologia, sociologia e ciência política - aqueles dos quais a sociologia escolar deve se ocupar4. Essa relação entre a sociologia (como nome) e as ciências sociais (como integrantes oficiais da disciplina escolar) nem sempre é inequívoca. Mesmo que se afirme oficialmente a participação das ciências sociais na

4- A menção às três disciplinas das ciências sociais é feita desde os Parâmetros Curriculares Nacionais para o Ensino Médio (BRASIL, 2000). 
composição da sociologia escolar, há diferenças no envolvimento de cada disciplina, dado que antropólogos e cientistas políticos mostram-se menos implicados em sua construção 5 .

Assim, além da pluralidade de "visões sociológicas" a constituir a própria sociologia, atenta-se também para outras heterogeneidades que a conformam, articuladas ao seu percurso no Brasil. A sociologia escolar foi instrumentalizada de diferentes modos, tendo sido ligada a finalidades cívicas, civilizadoras e de caráter positivista no início do século XX (MEUCCI, 2011). Com a abertura democrática nos anos 1980, a sociologia associa-se ao desenvolvimento do "pensamento crítico", figurando como parte dos "saberes necessários ao exercício da cidadania”, na Lei de Diretrizes e Bases de 1996. Foi esse, inclusive, um forte argumento para sua transformação em componente curricular obrigatório do ensino médio em 2008, por meio da Lei 11.684. Além disso, passada mais de uma década dessa Lei, a sociologia ainda é a disciplina com menor percentual de professores formados na área ${ }^{6}$. Ou seja, há uma diversidade grande de profissionais praticando a docência da sociologia. A evidência dessa pluralidade amplia-se internacionalmente ao considerarmos que em outros países a constituição de uma sociologia escolar ocorre de maneiras bastante distintas quanto ao estabelecimento de limites entre áreas de saber e à articulação entre políticas educacionais e acadêmicas ${ }^{7}$.

Com isso, dificilmente podemos considerar a sociologia como um todo coerente e homogêneo; menos ainda o que se entende por uma sociologia escolar. Se ficássemos apenas no âmbito das concepções teóricas e pedagógicas, a ideia de "levar" uma determinada sociologia à escola já demandaria maior complexifıcação. Nossos questionamentos avançam ao rejeitarmos a própria possibilidade desse consenso prévio. Pensando com Annemarie Mol, estendemos à sociologia a ideia de que não há ontologia - não há conformidade - que se defina anteriormente às práticas de conhecimento; a ontologia é realizada, "performada" nessas práticas (MARTIN; SPINK; PEREIRA, 2018, p. 301). Desse modo, não podemos chegar a um consenso do que seria a sociologia antes do encontro com os vários outros - humanos e não humanos, com seus corpos e agências - que compõem o seu ensino de modo situado, em uma perspectiva de saberes sempre "parciais", "localizados" (HARAWAY, 1995). Com isso, a sociologia não é meramente reproduzida - ou "levada" - do ambiente acadêmico-científico àquele da escola, ela é "coproduzida" nesse espaço (MOL, 2002; SCHWEIG, 2015b). Múltiplas sociologias têm emergido. Nesse sentido, pensar em um movimento de "levar a visão sociológica" à escola, longe de se constituir via de mão única ou de engendrar congruência, traz em si uma série de múltiplos e de potencialidades de composição.

\footnotetext{
5- Isso evidencia-se na própria avaliação dos livros didáticos pelo Ministério da Educação, que indica existir distribuição desigual dos temas e conteúdos das três áreas, com predomínio da Sociologia (BRASIL, 2017, p. 14). Também, no âmbito das associações científicas, apenas a Sociedade Brasileira de Sociologia está envolvida na promoção do Encontro Nacional de Ensino de Sociologia (ENESEB), não havendo articulação com as associações das outras duas áreas.

6- Conforme o Censo Escolar de 2018, apenas 28,4\% dos professores de sociologia tem formação adequada - licenciatura em ciências sociais ou bacharelado com complementação pedagógica (BRASIL, 2019).

7- A sociologia pode ser vista como componente dos social studies nos Estados Unidos, nos quais a antropologia pouco figura (DECESARE, 2014). Já no exemplo do Uruguai, o ensino de sociologia tem sua relação de maior proximidade com a área do direito (FERNANDEZ; OLIVEIRA, 2017).
} 


\section{“Para começar a fazer sociologia”}

0 que é necessário para se “começar a fazer sociologia” no ensino médio, como reivindica um dos bolsistas do PIBID? Conceitos, teorias, autores, análise de conjuntura? Embasar, expor, preparar? Como estabelecer a linha que separa a reflexão sociológica de outra não-sociológica? Podemos aproximar dessas questões ainda pela trajetória do ensino da sociologia no Brasil. Nela percebe-se uma hesitação quanto a um "começar", dada a não efetivação das primeiras propostas de inclusão da disciplina nos currículos escolares $^{8}$. Além dessa hesitação inicial, o olhar para a história mostra-nos que não foi necessária a constituição de um campo acadêmico-científico das ciências sociais no país para se "começar a fazer sociologia" na escola. Considerando que a inclusão oficial da disciplina ocorreu em 1925, pela Reforma Rocha Vaz, e o primeiro curso de ciências sociais data de 1933, na Escola Livre de Sociologia e Política de São Paulo (ELSP), não havia área consolidada nem cursos específicos de formação de professores à época da introdução da sociologia na escola. Sendo assim, ela era ministrada por profissionais com perfis diversos, como médicos, advogados e engenheiros (MORAES, 2011). Ou seja, antes da sociologia se consolidar como uma disciplina acadêmica, práticas nomeadas como "ensino de sociologia" já ocorriam no país. Ademais, pode-se dizer que o percurso da sociologia no ensino médio esteve marcado por vários "re-começos", entre retiradas e reinserções da disciplina, de acordo com as diferentes políticas educacionais do país.

Diante desse cenário, soma-se o fato de que o campo acadêmico-científico demorou a se implicar no debate a respeito do ensino de sociologia. É somente com o movimento mais recente em torno da obrigatoriedade que vemos surgir o interesse de pesquisadores das ciências sociais pelo tema. Como relata Luiza Helena Pereira (2013), a mobilização pela reintrodução da sociologia no ensino médio iniciou-se em maior grau por parte de entidades profissionais, como os sindicatos de sociólogos e a Federação Nacional dos Sociólogos nos anos 1990. Apenas posteriormente o ensino de sociologia ganhou legitimidade enquanto objeto de produção de conhecimento e, consequentemente, espaço de maior visibilidade em eventos acadêmicos ${ }^{9}$. Desse modo, podemos entender que esse mais recente "re-começar" da sociologia na escola, por meio da lei 11.684 de 2008, apresenta contornos bastante específicos. É a primeira vez, de fato, que se vê um esforço coletivo de construção de parâmetros de ensino a partir do campo acadêmico-científico. Entretanto, como mostram Meucci; Bezerra (2014), recentes estabilizações a respeito de balizas para o ensino da sociologia escolar não são consequências apenas dessas elaborações acadêmicas, mas constituem-se também a partir de outros elementos. Os autores assinalam o Plano Nacional do Livro Didático, o Exame Nacional do Ensino Médio e os modelos de formação

\footnotetext{
8- No final do século XIX, registram-se duas tentativas de inserção da sociologia como disciplina na escola secundária. No entanto, nem o projeto de lei do deputado Rui Barbosa, de 1882, nem a mudança proposta pelo ministro Benjamin Constant, em 1890, foram efetivadas. Somente a Reforma Rocha Vaz, de 1925, torna a sociologia obrigatória nos anos finais dos cursos secundários, durando até a Reforma Capanema, de 1942, a qual retira a sociologia dos currículos.

9- É apenas em 2005 - às vésperas do Parecer CNE 38/2006, que já sinalizava a obrigatoriedade da sociologia no ensino médio - que a Sociedade Brasileira de Sociologia (SBS) cria uma Comissão de Ensino. Nesse mesmo ano, um grupo de trabalho sobre ensino de sociologia é criado no Congresso Brasileiro de Sociologia.
} 
docente nas licenciaturas como tendo papel fundamental na rotinização dos conteúdos a serem ensinados em nome da sociologia na escola (MEUCCI; BEZERRA, 2014).

Sendo assim, ao enfatizar o caráter incipiente da aproximação entre sociologia escolar e campo acadêmico-científico, além de seus vários "re-começos", chamo atenção para a existência de uma multiplicidade de práticas e agentes que têm constituído o que seja o ensino de sociologia ao longo de quase um século. Ao trazer isso à tona, deslocamosnos de perspectivas mais prescritivas, preocupadas em delinear "o quê, como e por que ensinar" sociologia. Inspirando-se no que propõe Latour (2012), em sua "sociologia das associações", o trabalho dos cientistas sociais poderia ser menos o de recrutar e estabilizar a lista de agrupamentos que compõem o social e mais o de rastrear os instrumentos que possibilitam a estabilização das controvérsias - incluindo-se aí a estabilização das próprias ciências sociais. Transpondo essa sugestão para pensar o ensino, seguimos outros caminhos para responder à questão posta sobre o que é necessário para "começar a fazer sociologia". Esse "começar" pode ser visto como um constante "re-começar" - ou um "começar pelo meio" - sempre compondo com práticas que já estão em curso e com elementos que vão além do que se entende por uma "intenção" teórica ou pedagógica.

\section{“Preparação prévia” para ter um “embasamento”}

Voltando à situação narrada, percebemos que a controvérsia do planejamento tocou uma outra questão: a necessidade de "embasamento" e "preparação prévia". Que tipo de preparação é necessária para começar a fazer sociologia na escola? Diante de várias heterogeneidades, o que é "ter um embasamento"? Essas perguntas remetem a outras falas que foram ouvidas recorrentemente durante a pesquisa de campo e que dizem respeito à problemática da formação docente. Em tom de crítica, ao refletirem acerca de sua formação no curso de licenciatura, grande parte dos professores de sociologia repetiam: “a Universidade não prepara para a docência”. Como causas, alegavam a distância entre as discussões teóricas da faculdade e a realidade da escola; o fato de se sentirem aptos para “teorizar" sobre a escola, mas não para a "prática” da docência (SCHWEIG, 2015a). Chama atenção nessas críticas um entendimento de que percepções e habilidades possam ser de algum modo incorporadas, independentemente do engajamento com os ambientes nos quais são desenvolvidas. Dizendo de outro modo: frequentemente espera-se que o espaço da universidade torne alguém apto a um tipo de atividade que não faz parte daquele ambiente, concebendo a formação profissional em termos de transferência ou aplicação de teorias a contextos externos de prática.

A ideia de que é possível "ter um embasamento" e estar "previamente preparado" à prática, e à ação no mundo, dialoga com determinados pressupostos de cisão entre sujeito e objeto; mente e corpo; teoria e prática. Tais pressupostos ainda permeiam, em boa medida, currículos e cursos de formação de professores. Podemos identificar nesse modo de conceber o ensino a lógica do pensamento hilemórfico aristotélico, que funda a relação entre forma e matéria. Segundo ele, a matéria tem uma condição de passividade, à espera de um agente que irá lhe dar uma forma de acordo com a finalidade que tem em mente (INGOLD, 2012, p. 26). Há, portanto, a primazia da razão como ordenadora do mundo, por 
meio da proposição de um delineamento teórico anterior, que desconsidera a potência dos corpos e dos materiais em fluxo.

Assim, no âmbito do ensino de sociologia, caberia ao professor "levar a visão sociológica" aos estudantes como forma. No cotidiano escolar, restaria aos estudantes apreender intelectualmente essa forma para aplicá-la a uma matéria - seja a exemplos de suas experiências ou a uma prova, um "trabalhinho", isto é, produtos que possam se transformar em instrumentos de avaliação ou medição da aprendizagem. Ainda na controvérsia narrada, podemos observar a lógica do modelo hilemórfico, e a cisão via mediação racional, operar em diferentes gradações - desde a ênfase no "embasamento por meio da preparação prévia" (fundamentação teórica e histórica), à "aula expositiva seguida de debate" (isto é, como condição dele), até a reivindicação do próprio "debate" como anterior à produção do estêncil. Instituem-se, portanto, etapas que se sucedem no tempo e aparecem como pré-condição uma da outra: embasar; expor; debater; praticar. Organiza-se, portanto, uma sequência de tentativas de contenção das "recalcitrâncias" (LATOUR, 2007) que o ambiente, a materialidade e a corporalidade oferecem ao próprio processo de conhecer.

Entretanto, na própria controvérsia narrada é possivel perceber fissuras a esse modelo, dado que ele não se mostra consensual. Alguns de seus limites evidenciam-se e há quem os sinalize por meio da reivindicação de maior protagonismo aos estudantes. No entanto, pode-se ir mais além. Na discussão, uma importante pista aparece: o bolsista que mais tensiona esse modelo tem uma trajetória como ator e professor de teatro, tendo optado por estudar licenciatura em ciências sociais como complementação à sua atuação nas artes. É ele quem propõe uma inversão na lógica do planejamento, ao indicar que "se comece pelo fazer" do estêncil. Essa virada permite recolocar a questão da preparação para a docência em outros termos que não os da incorporação de conceitos ou habilidades anteriores ao engajamento com o mundo. Desse modo, sua condição de docente-artista convida-nos a investigar como os fazeres artísticos poderiam contribuir nessa tarefa.

\section{“O próprio fazer seria problematizador”}

Ao discorrer a respeito da metodologia da pesquisa em artes plásticas, Jean Lancri sugere o "começar pelo meio" - inspirando-se em Gilles Deleuze e Paul Valéry - como resposta aos estudantes que lhe perguntam "por onde começar". Em suas palavras: "De onde partir? Do meio de uma prática, de uma vida, de um saber, de uma ignorância. Do meio desta ignorância que é bom buscar o âmago do que se crê saber melhor" (LANCRI, 2002, p. 18). Isso é, longe de um trabalho de execução ou aplicação de elaborações conceituais, o que Lancri propõe é que a investigação nas artes não ocorre nos marcos de um $a$ priori teórico. A arte trabalha com conceitos provisórios, táticos - por vezes contraditórios - sendo sua validade julgada "apenas por sua necessária invalidação futura" (LANCRI, 2002, p. 27). Nessa lógica, portanto, assume-se que o "trajeto” guia a investigação em substituição ao "projeto" inicial.

Isso ocorre, pois pesquisar nas artes plásticas é assumir que o trabalho opera em um "meio caminho" entre o conceitual e o sensível, entre a razão e a imaginação, entre o intelectual e o material. Ou seja, não toma como ponto de partida um mundo 
ou uma matéria imutáveis que servem apenas como suporte a ideias pré-formuladas. Do contrário, a materialidade desafia a todo tempo seus pressupostos, fazendo com que sejam subvertidos e recompostos, indicando a busca por esse "meio caminho". Fernanda Eugenio e João Fiadeiro (2013) também lançam mão do "começar pelo meio", no sentido de um "começar pelo imprevisível” e não por balizas já conhecidas, controladas. Eles sugerem que aguentemos "ficar no meio", que suportemos o não saber, tornando o imprevisível uma "zona de atenção". Desse modo, "já não há uma procura por respostas, mas uma navegação pelas perguntas que a teia de relações ali presentes nos oferece” (EUGENIO; FIANDEIR0, 2013, p. 225).

Assim, ao propor "começar" pela produção do estêncil, o docente-artista de nosso relato propõe iniciar pelo campo imprevisível do "fazer", daquilo que não está enquadrado numa forma dada por uma suposta "visão sociológica" previamente acordada. Desse modo, ele sustenta uma possibilidade de questionamento à lógica hilemórfica, alocando o "fazer" não como uma duplicação ou aplicação de representações mentais à matéria, mas como o caminho próprio da aprendizagem ${ }^{10}$. Chama atenção o modo como ele justifica a proposição de começar pelo estêncil: "poderiam "ver' o que eles estão pensando". Ou seja, "começar pelo fazer" restitui a materialidade do próprio pensar. Essa indicação aproximase ao que Tim Ingold nomeia como "pensar por meio do fazer", como alternativa ao "fazer por meio do pensar". Conhecer pelo "fazer" teria um caráter processual; seria um acompanhar desdobramentos. 0 conhecimento não é "adquirido", mas "cresce”, já que as propriedades dos materiais não são fixas, enquanto atributos permanentes, mas são continuamente emergentes (INGOLD, 2013).

0 "fazer" também remonta à noção de affordance, de James Gibson (1979), a partir da qual se entende a percepção não como uma atuação da mente, mas de um organismo como um todo - mente e corpo - ativamente engajado ao seu entorno; atento àquilo que o ambiente oferece e dispõe. Essa definição evidencia propriamente o corpo e a materialidade como produtores de conhecimento. Como explora Carolina Camargo de Nadai, em sua pesquisa em dança, a ideia de affordance indica um movimento de percepção corporal ou de "disponibilizância", que "propicia captar disponibilidades no ambiente e como elas geram possíveis encontros, relações, ações em um perceber-fazer” (NADAI, 2017, p. 60). Assim, esses modos de pesquisar em arte - por estarem mais sensíveis às diferentes agências na composição de suas produções - potencializam uma passagem da perspectiva representacional à abordagem performativa, dada a indissociabilidade entre investigação e criação. Logo, com as pistas indicadas pela investigação artística, podemos tomar outras direções para conceber o ensino de sociologia, considerando a centralidade do "fazer" como modo de conhecer.

\section{Recompor as peças do planejamento pedagógico}

Como consequência, passamos a questionar-nos acerca de possíveis maneiras de planejar intervenções pedagógicas que "comecem pelo meio de um fazer" para produzir conhecimento sociológico. Como propor intervenções que tomem enquanto potência -

10 - Como na frase de Soulanges, citada por Lancri: "0 que faço, ensina-me o que procuro" (LANCRI, 2002, p. 27). 
e não como fragilidade - a ideia de que a sociologia não é um todo coerente anterior às práticas e aos encontros? Quais seriam as possíveis implicações de uma inversão no esquema "embasar; expor; debater; praticar"? "Começar pelo meio de um fazer" requer trilhar um caminho que admite o conhecer menos como uma "descrição" (ou explicação, ou interpretação) de uma realidade dada, e mais propriamente como "criação" de mundos, enquanto composição com diversos outros. Assim, o ato de ensinar não teria relação com transmissão ou exposição por parte do professor, mas com uma cocriação. Pensando com Latour (2007) em seu diálogo com os trabalhos de Isabelle Stengers e Vinciane Despret, a produção de conhecimento seria mais uma questão de "articulação" - ou afetação - e menos de "referência".

Nesse sentido, o "começar pelo meio de um fazer", enquanto proposição de atenção a práticas em curso, envolve sustentar uma abertura ao não saber, um contato com o inesperado da materialidade e do pensar com o corpo; com o "acontecimento" e seus “acidentes" (DELEUZE, 2003). Ao invés da "exposição”, de um fechamento em significados, afırmações, explicações e interpretações, aproximamo-nos da ideia de experimentação de "proposições"11 - não como afırmações defınitivas ${ }^{12}$, mas como convites a uma composição (LATOUR, 2007). 0 “debater”, menos do que a explicitação de posições já definidas, opiniões ou mesmo de perspectivas teóricas, pode se configurar como um convite à mobilização de "mediadores" ${ }^{13}$, instituindo a busca por outros objetos, linguagens, conceitos, instrumentos - em distintas possibilidades de tradução de um mundo que se difere a todo instante. Com isso, afastamo-nos também da ideia de "embasamento", em favor da noção de "articulação", de criação de conexões com outros fenômenos, conceitos, pessoas, experiências, tomando o conhecimento como ampliação de redes na confecção de mundos. Nesse sentido, teríamos um caminho que não se ancora em "fundamentações" ou em busca de "coerências", mas avança na direção da formação de "consistências" (DELEUZE; GUATTARI, 1997; EUGENIO; FIADEIRO, 2013).

Esse rearranjo exige colocar em outros termos o próprio trabalho do professor e a noção de "preparação". Praticar a docência envolveria sustentar "ficar no meio" por mais tempo, acompanhando o desenrolar do mundo enquanto processo. Exigiria fugir à tentação da "narrativa épica da razão crítica" em favor do cultivo da "arte da atenção imanente" - tal como as bruxas de Isabelle Stengers (2017). "Preparar-se”, ao invés de ocorrer no sentido de se colocar "pronto", preenchido de conteúdo, referências e quadros explicativos, poderia se transformar num colocar-se de "prontidão", com a sensibilidade alargada a um porvir. A atitude inicial voltada à organização de uma "exposição" passa a um colocar-se "à disposição" do outro; do inesperado. Dessa forma, a dedicação à preparação se move em direção a uma conexão com per-cursos, com os movimentos das

11- A partir da leitura do filósofo Alfred Norton Whitehead feita por Isabelle Stengers, Latour (2007) utiliza o termo "proposição" em função de três elementos fundamentais, que também nos são úteis para explorar possibilidades de abertura na aproximação com a experiência do fazer. Segundo 0 autor: "Proposição: a) denota uma obstinação (posição), que b) não têm uma autoridade definitiva (é apenas uma pro-posicão) e c) pode aceitar negociar-se a si própria para formar uma com-posicão sem perder solidez." (LATOUR, 2007, p. 45).

12- Podemos aproximar aqui da ideia de "conceitos táticos" ou "provisórios", de Lancri (2002).

13- Latour elabora a noção de "mediador" em oposição à de "intermediário". As entidades se comportariam como mediadores na medida em que permitam produzir modificações - sua singularidade faz diferença no conjunto das relações. Como intermediários, as entidades tendem a transpor o que já está dado, reiterando uma estabilização (LATOUR, 2012). 
trajetórias de objetos de conhecimento, do mundo se mundificando e do próprio "eu" enquanto acontecimento - também fruto de uma série de "acidentes” (DELEUZE, 2003).

Nesse conectar percursos, colocamo-nos de "prontidão" ao reconhecermos o que temos, enquanto potência em nossas trajetórias, e que pode ser colocado "à disposição" daquilo que está ali. Reconhecemos e colocamos à disposição as multiplicidades e potencialidades que a sociologia e as ciências sociais podem oferecer - por isso a importância de um trabalho minucioso de abertura de suas caixas-pretas. Sendo assim, a prática da docência se liga ao desenvolvimento de uma atenção à emergência constante das propriedades de si e do mundo. Desse modo, tal movimento requer distanciar-se de um "plano de princípio ou finalidade" (DELEUZE; GUATTARI, 1997, p. 222). Em outras palavras, trata-se do descentramento da "intenção" para que se consiga desenvolver uma "atenção" ao acontecimento, demandando proposições menos normativas, ou prescritivas, a respeito da prática da docência.

Sendo assim, colocar a docência da sociologia em outros termos foi possivel por meio do exercício da sensibilidade etnográfica, ao se interceptar um momento singular em que certezas quanto ao planejamento pedagógico e à prática docente estavam em negociação. A situação narrada neste artigo dá conta de um momento privilegiado de abertura em vários sentidos, dado que é protagonizada por licenciandos, professores em formação, na ausência das figuras de autoridade como os professores efetivos das escolas, supervisores do PIBID, ou as professoras orientadoras da Universidade. Além disso, o encontro só foi possível em um instante de greve do magistério, quando a rotina de atividades da escola e do próprio PIBID teve sua normalidade interrompida ${ }^{14}$. A singularidade da situação complementa-se com a presença de um estudante de licenciatura que é ator e havia sido professor de teatro, referido aqui como docente-artista. Ao longo do trabalho de campo, sua presença, tanto no PIBID quanto no estágio docente da licenciatura, provocou outros momentos de desestabilização de certezas quanto ao que seria ensinar sociologia ${ }^{15}$, fazendo-nos investigar as contribuições dos modos de fazer artísticos ao ensino de ciências sociais.

A inflexão desenvolvida aqui permitiu evidenciar uma série de divergências e tensões que perpassam o que temos estabilizado enquanto ensino de sociologia no ensino médio. Com o trabalho de tomar a sociologia menos como "ciência do social" e mais como "busca de associações", entendemos o "social" não como um dado domínio específico, mas como fruto de um movimento de constante reassociação e reagregação (LATOUR, 2012). Ao levar mais adiante as operações de "estranhamento" e "desnaturalização" reivindicadas à sociologia escolar (BRASIL, 2006), a perspectiva aqui desenvolvida permite ver o trabalho do professor não apenas como daquele que evoca o "social" enquanto explicador dos temas e fenômenos que ensina, mas também como alguém que opera e facilita conexões; alguém que acompanha processos e cria alianças. No caso da presente pesquisa, explorar conexões com os modos de produzir conhecimento nas artes, por exemplo, indicou um potencial caminho no alargamento de redes na confecção de mundos.

14 - A provisoriedade dessa abertura fez com que de fato não fossem realizadas as atividades tais como discutidas naquele dia, tomando outras formas nas escolas.

15- Ver especialmente Schweig (2015a, p. 92). 


\section{Conclusão}

A partir da inexistência de uma ontologia prévia às práticas, perseguimos neste texto algumas de suas consequências para a prática da docência da sociologia no ensino médio. Percorremos elementos da trajetória da sociologia escolar no Brasil de modo a atentar ao seu caráter heterogêneo, fruto de uma série de agenciamentos que vão além de questões epistemológicas das ciências sociais. Além disso, mesmo com um avanço em torno de algumas estabilizações, o caráter recente da aproximação entre a sociologia escolar e o campo acadêmico-científico evidencia um objeto não acabado, constituindo-se entre dissonâncias e tensões. Sendo assim, mesmo reconhecendo a emergência de esforços na criação de parâmetros para o ensino de sociologia desde as ciências sociais acadêmicas, buscamos atentar aqui para as porosidades inerentes ao próprio processo de produção do conhecimento. À parte de alguns delineamentos normativos - como referenciais teóricos, currículos, parâmetros, orientações e bases curriculares - acolhemos o fato de que no cotidiano da docência a sociologia volta a se abrir em controvérsias.

Assim, ao invés de considerarmos essas heterogeneidades como fragilidade ou impotência das práticas da docência da sociologia, enfatizamos a força que reside em sua capacidade de composição na criação de mundos. Como afırma Latour: "não se pode chegar a nenhum mundo comum se aquilo que é comum já tiver sido decidido pelos cientistas, longe da vista daqueles cujas 'comunalidades' estão assim a ser construídas" (LATOUR, 2007, p. 56). Ou seja, é no reconhecimento da heterogeneidade e do não acabamento que admitimos a necessidade de estabelecer relações.

Nesse sentido, aposta-se na ideia de "começar pelo meio de um fazer" enquanto um imaginar possibilidades ao conhecimento como articulação de múltiplos, superando dicotomias ao evidenciar a indissociabilidade entre matéria e significado. Como vimos, reformular a prática da docência em consonância com esse modo de operar engendra o desafio de afastar-se de domínios mais finalísticos, passando-se a cultivar a atenção aos processos e percursos, acolhendo recalcitrâncias. Sendo assim, apostamos em uma inversão e transmutação não para sugerir modelos acabados, mas como uma "proposição", a qual, em composição com a sensibilidade etnográfica e os modos de fazer artísticos, possibilitou formular novas perguntas e sugerir outras alianças no fortalecimento do ensino de sociologia.

\section{Referências}

BRASIL. Instituto Nacional de Estudos e Pesquisas Educacionais Anísio Teixeira. Resumo técnico: censo da educação básica 2018. Brasília, DF: INEP, 2019.

BRASIL. Ministério da Educação. Orientações curriculares nacionais para o ensino médio. Brasília, DF: MEC, 2006. Disponível em: http://portal.mec.gov.br/seb/arquivos/pdf/book_volume_03_internet.pdf. Acesso em 16 de abr. 2019.

BRASIL. Ministério da Educação. Parâmetros Curriculares Nacionais para 0 Ensino Médio: pt. 4. ciências humanas e suas tecnologias. Brasilia, DF: MEC, 2000. Disponível em: http://portal.mec.gov.br/ seb/arquivos/pdf/cienciah.pdf. Acesso em: 27 abr. 2019. 
BRASIL. Ministério da Educação. Secretária de Educação Básica. PNLD 2018: sociologia - guia de livros didáticos. Ensino médio. Brasília, DF: MEC, 2017.

DECESARE, Michael. 95 anos de ensino de sociologia no ensino médio. Educação \& Realidade, Porto Alegre, v. 39, n. 1, p. 113-137, mar. 2014. Disponível em: http://www.scielo.br/scielo.php?script=sci_ arttext\&pid=S2175-62362014000100008\&lng=pt\&nrm=iso. Acesso em: 10 abr. 2019.

DELEUZE, Gilles. Lógica do sentido. São Paulo: Perspectiva, 2003.

DELEUZE, Gilles; GUATTARI, Félix. Mil platôs: capitalismo e esquizofrenia. v. 5. São Paulo: Ed. 34, 1997.

EUGENIO, Fernanda; FIADEIRO, João. Jogo das perguntas: 0 modo operativo «AND» e 0 viver juntos sem ideias. Fractal, Rio de Janeiro, v. 25, n. 2, p. 221-246, ago. 2013. Disponível em: http://www.scielo.br/ scielo.php?script=sci_arttext\&pid=S1984-02922013000200002\&lng=en\&nrm=iso. Acesso em: 24 abr. 2019.

FERNANDEZ, Daniela; OLIVEIRA, Amurabi. As outras histórias da sociologia escolar na América Latina: um olhar desde o Uruguai com Daniela Fernandez. Cadernos da Associação Brasileira de Ensino de Ciências Sociais, Rio de Janeiro, v. 1, n. 2, p.134-141, 2017.

GIBSON, James. The ecological approach to visual perception. Boston: Houghton Mifflin, 1979.

HARAWAY, Donna. Saberes localizados: a questão da ciência para o feminismo e o privilégio da perspectiva parcial. Cadernos Pagu, Campinas, v. 5, p. 7-41, 1995.

INGOLD, Tim. Trazendo as coisas de volta à vida: emaranhados criativos num mundo de materiais. Horizontes Antropológicos, Porto Alegre, v.18, n.37, p. 25-44, jun. 2012. Disponível em: http://www. scielo.br/scielo.php?script=sci_arttext\&pid=S0104-71832012000100002\&lng=en\&nrm=iso. Acesso em: 24 abr. 2019.

INGOLD, Tim. Making: anthropology, archaeology, art and architecture. London: Routledge, 2013.

LANCRI, Jean. Colóquio sobre a metodologia da pesquisa em artes plásticas na universidade. In: BRITES, Blanca; TESSLER, Elida (org.). 0 meio como ponto zero: metodologia da pesquisa em artes plásticas. Porto Alegre: UFRGS, 2002. p.16-33.

LATOUR, Bruno. Como falar do corpo? A dimensão normativa dos estudos em ciência. In: NUNES, João Arriscado; ROQUE, Ricardo (org.). Objetos impuros: experiências em estudos sociais da ciência. Porto: Afrontamento, 2007. p. 40-61.

LATOUR, Bruno. Jamais fomos modernos: ensaio de antropologia simétrica. Rio de Janeiro: Ed. 34, 1994. LATOUR, Bruno. Reagregando o social: uma introdução à teoria do Ator-Rede. Salvador: UFBA: USC, 2012.

LIMA, Nathan Willig; OSTERMANN, Fernanda; CAVALCANTI, Claudio Jose de Holanda. A não-modernidade de Bruno Latour e suas implicações para a educação em ciências. Caderno Brasileiro de Ensino de Física, Florianópolis, v. 35, n. 2, p. 367-388, ago. 2018. 
MARTIN, Denise; SPINK, Mary Jane; PEREIRA, Pedro Paulo Gomes. Corpos múltiplos, ontologias políticas e a lógica do cuidado: uma entrevista com Annemarie Mol. Interface, Botucatu, v. 22, n. 64, p. 295-305, mar. 2018. Disponível em: http://www.scielo.br/scielo.php?script=sci_arttext\&pid=S141432832018000100295\&lng=en\&nrm=iso. Acesso em: 11 abr. 2019.

MEUCCI, Simone. Institucionalização da sociologia no Brasil: primeiros manuais e cursos. São Paulo: Hucitec: Fapesp, 2011.

MEUCCI, Simone; BEZERRA, Rafael Ginane. Sociologia e educação básica: hipóteses sobre a dinâmica de produção de currículo. Revista de Ciências Sociais, Fortaleza, v. 45, n. 1, p. 87-101, 2014.

MOL, Annemarie. The body multiple: ontology in medical practice. Durham: Duke University Press, 2002.

MORAES, Amaury Cesar. Ensino de sociologia: periodização e campanha pela obrigatoriedade. Caderno Cedes, Campinas, v. 31, n. 85, p. 359-382, set. /dez. 2011.

NADAl, Carolina Camargo de. Gambiarração: poéticas em composição coreográfica. 2017. Tese (Doutorado em Teoria e Prática do Teatro) - Escola de Comunicações e Artes, Universidade de São Paulo, São Paulo, 2017.

PEREIRA, Luiza Helena. A luta dos sociólogos pela obrigatoriedade da sociologia no ensino médio. In: MEIRELLES, Mauro; RAIZER, Leandro; PEREIRA, Luiza Helena (org.). 0 ensino de sociologia no RS: repensando o lugar da sociologia. Porto Alegre: Evangraf/Laviecs, 2013. p. 13-34.

SCHWEIG, Graziele Ramos. Aprendizagem e ciência no ensino de sociologia na escola: um olhar desde a antropologia. 2015. Tese (Doutorado em Antropologia Social) - Universidade Federal do Rio Grande do Sul, Porto Alegre, 2015a.

SCHWEIG, Graziele Ramos. Antropologia da ciência e educação: reflexões sobre a sociologia no ensino médio sob o idioma da coprodução. Educação Unisinos, São Leopoldo, v. 19, n. 3, p. 335-344, set./dez. 2015 b. Disponível em: http://revistas.unisinos.br/index.php/educacao/article/view/edu.2015.193.04/4887. Acesso em 24 mar. 2020.

SOUZA, lara Maria de Almeida. A Noção de Ontologias Múltiplas e suas Consequências Políticas. Ilha, Florianópolis, v. 17, n. 2, p. 49-73, ago./dez. 2015.

STEIL, Carlos Alberto; CARVALHO, Isabel Cristina de Moura. Epistemologias ecológicas: delimitando um conceito. Mana, Rio de Janeiro, v. 20, n. 1, p. 163-183, abr. 2014. Disponível em: http://www.scielo.br/scielo. php?script=sci_arttext\&pid=S0104-93132014000100006\&lng=en\&nrm=iso. Acesso em: 24 mar. 2019.

STENGERS, Isabelle. Reativar o animismo. Caderno de leituras. Chão da Feira, Belo Horizonte, n. 62, p. 2-15, 2017. Disponível em: http://chaodafeira.com/wp-content/uploads/2017/05/caderno-62-reativar-ok.pdf. Acesso em: 24 mar. 2019.

TADDEI, Renzo; GAMBOGGl, Ana Laura. Educação, antropologia, ontologias. Educação e Pesquisa, São Paulo, v. 2, n. 1, p. 27-38, jan./mar. 2016. Disponível em: http://www.scielo.br/scielo.php?script=sci_ arttext\&pid=S1517-97022016000100027\&lng=pt\&nrm=iso. Acesso em: 29 mar. 2019. 
VIVEIROS DE CASTRO, Eduardo. Perspectivismo e multinaturalismo na América indígena. In: VIVEIROS DE CASTRO, Eduardo. A inconstância da alma selvagem e outros ensaios de antropologia. São Paulo: Cosac \& Naify, 2002. p. 345-399.

Recebido em: 08.05.2019

Revisado em: 01.10.2019

Aprovado em: 24.03.2020

Graziele Ramos Schweig é professora adjunta do Departamento de Métodos e Técnicas de Ensino da Faculdade de Educação da Universidade Federal de Minas Gerais (UFMG). É bacharel e licenciada em ciências sociais pela Universidade Federal do Rio Grande do Sul (UFRGS), mestre e doutora em antropologia social pelo PPGAS/UFRGS. 